\title{
The Association of Mounier-Kuhn Syndrome and Pulmonary Aspergillomas: A Case Report
}

\author{
Recep Akgedik ${ }^{1}$, Canan Eren Dağl1 ${ }^{1}$, Ali Bekir Kurt², Hasan Öztürk², Nilay Taş ${ }^{3}$ \\ ${ }^{1}$ Department of Pulmonology, Ordu University School of Medicine, Ordu, Turkey \\ ${ }^{2}$ Department of Radiology, Ordu University School of Medicine, Ordu, Turkey \\ ${ }^{3}$ Department of Anesthesiology, Ordu University School of Medicine, Ordu, Turkey
}

A 60-year-old woman was admitted to our hospital with dyspnea, a cough and hemoptysis. She had a history of long-term treatment of asthma and recurrent lower respiratory tract infections. She had been hospitalized twice in the previous 3 years to treat non-massive hemoptysis caused by cystic bronchiectasis, but without pulmonary aspergillomas. Chest computed tomography (CT) revealed tracheobronchomegaly involving the entire trachea and main bronchi. The transverse and sagittal diameters of the trachea were 36.5 and $29.9 \mathrm{~mm}$, respectively. Diverticula were evident in the posterolateral proximal tracheal wall and cystic bronchiectasis with pulmonary aspergillomas was detected in both lower lung lobes (Figure 1). Fiberoptic bronchoscopy revealed a dilated trachea, diverticula in the posterolateral region of the proximal tracheal wall, and enlargement of both main bronchi. The cartilage rings of the trachea and main bronchi were notably prominent. Mucosal atrophy of both the trachea and bronchi was also evident (Figure 2). Pathological examination of bronchial lavage specimens revealed septate hyphae typical of Aspergillus spp.; the septae branched at a $45^{\circ}$ angle. In the absence of any secondary cause of the tracheobronchial dilation, we diagnosed Mounier-Kuhn syndrome (MKS) with tracheal diverticula and pulmonary aspergillomas. Oral itraconazole and tranexamic acid were started. Although we advised surgery to counter the probably life-threatening massive he- moptysis, the patient refused. She recovered rapidly from the hemoptysis, which did not recur. The patient continues on oral itraconazole and has been followed without complications for two months.

Mounier-Kuhn Syndrome or tracheobronchomegaly is a rare congenital abnormality characterized by marked dilation of the trachea and main bronchi caused, in turn, by atrophy or lack of elastic tissue and the muscularis mucosae of the major airways $(1,2)$. MKS is diagnosed radiographically and bronchoscopically when chest CT reveals (female/male) tracheal transverse diameters $>21 / 25 \mathrm{~mm}$ and sagittal diameters $>23 / 27 \mathrm{~mm}$, and when the transverse diameters of the right and left main bronchi are $>19.8 / 21.1$ and $>17.4 / 18.4 \mathrm{~mm}$, respectively $(3,4)$. MKS features three subtypes: the first is characterized by slight symmetrically diffuse enlargement of the major airways; the second obvious and distinct airway enlargement with diverticula; and the third diverticula or sacculations extending to the distal bronchi $(1,4)$.

Mounier-Kuhn Syndrome is often complicated by recurrent lung infections and bronchiectasis. Treatment strategies are diverse, ranging from respiratory physiotherapy to endobronchial stenting (4). To our knowledge, this is the first case of MKS featuring a tracheal diverticulum and concomitant pulmonary aspergillomas.

Written patient consent was obtained for publication.

This study was presented at TÜSAD $37^{\text {th }}$ National Congress 17-21 November 2015, İmir, Turkey.

Address for Correspondence: Dr. Recep Akgedik, Department of Pulmonology, Ordu University School of Medicine, Ordu, Turkey Phone: +905416000552re-mail: recepakgedik@hotmail.com

Received: 13 April 2015 Accepted: 19 December 2015 • DOI: 10.5152/balkanmedj.2016.150397

Available at www.balkanmedicaljournal.org 

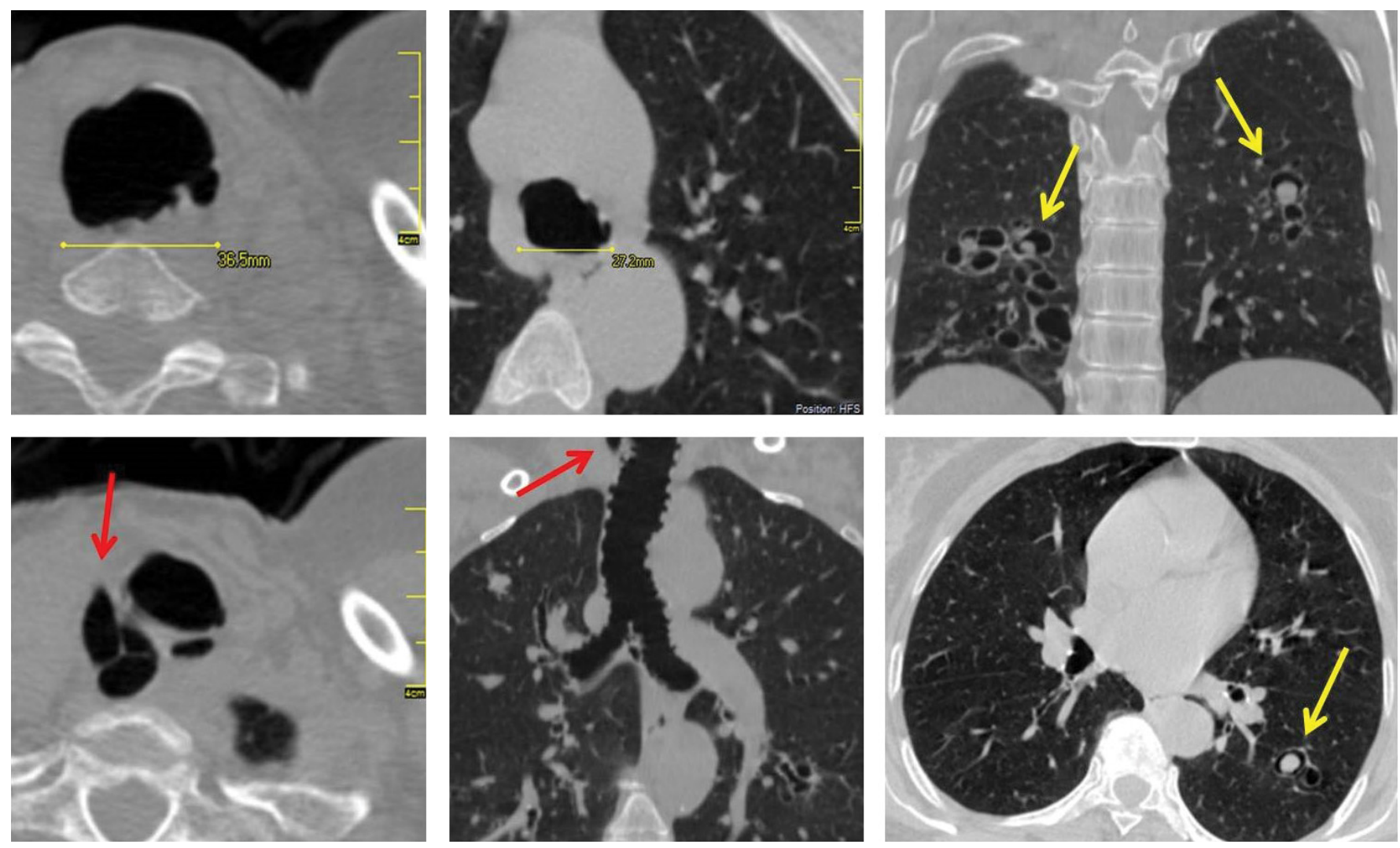

FIG. 1. Chest computed tomography reveals a dilated trachea, diverticula of the posterolateral tracheal wall (red arrows), and distal bronchiectasis with pulmonary aspergillomas (yellow arrows).

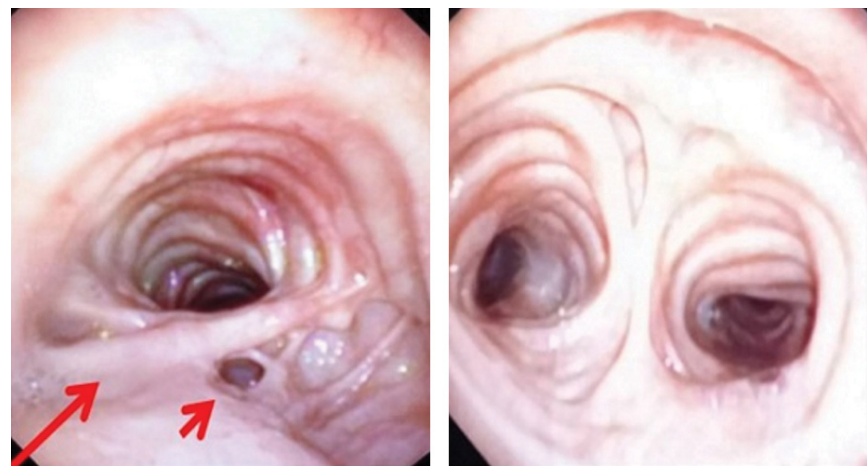

FIG. 2. Fiberoptic bronchoscopy reveals tracheobronchomegaly and the orifice of the tracheal diverticulum (red arrows).

\section{Ethics Committee Approval: N/A.}

Informed Consent: Written informed consent was obtained for this study.

Peer-review: Externally peer-reviewed.

Author contributions: Concept - R.A.; Design - R.A.; Supervision - R.A., H.Ö.; Resource - A.B.K., H.Ö., N.T., C.E.D.; Materials - R.A., A.B.K., H.Ö.; Data Collection and/or Processing - R.A., A.B.K., H.Ö., N.T.; Analysis and/or Interpretation - R.A., A.B.K.,
C.E.D.; Literature Search - C.E.D., N.T., H.Ö.; Writing - R.A., A.B.K.; Critical Reviews - R.A., A.B.K.

Conflict of Interest: No conflict of interest was declared by the authors.

Financial Disclosure: The authors declared that this study has received no financial support.

\section{REFERENCES}

1. El-Kersh K, Yasin M, Cavallazzi R, Perez RL. Mounier-Kuhn syndrome. Imaging and bronchoscopic findings. Am J Respir Crit Care Med 2014;1;190:e2-3.

2. Lazzarini-de-Oliveira LC, Costa de Barros Franco CA, Gomes de Salles CL, de Oliveira AC Jr. A 38-year-old man with tracheomegaly, tracheal diverticulosis, and bronchiectasis. Chest 2001;120:1018-20. [CrossRef]

3. Woodring JH, Howard RS 2nd, Rehm SR. Congenital tracheobronchomegaly (Mounier-Kuhn syndrome): a report of 10 cases and review of the literature. $J$ Thorac Imaging 1991;6:1-10. [CrossRef]

4. Menon B, Aggarwal B, Iqbal A. Mounier-Kuhn syndrome: report of 8 cases of tracheobronchomegaly with associated complications. South Med J 2008;101:83-7. [CrossRef] 